\title{
Effects of once-weekly semaglutide vs once-daily canagliflozin on body composition in type 2 diabetes: a substudy of the SUSTAIN 8 randomised controlled clinical trial
}

\author{
Rory J. McCrimmon ${ }^{1}$ • Andrei-Mircea Catarig ${ }^{2}$ • Juan P. Frias ${ }^{3} \cdot$ Nanna L. Lausvig $^{2} \cdot$ Carel W. le Roux $^{4}$. \\ Desirée Thielke $^{2} \cdot$ Ildiko Lingvay $^{5}$
}

Received: 5 September 2019 / Accepted: 6 November 2019 / Published online: 2 January 2020

(C) The Author(s) 2020

\begin{abstract}
Aims/hypothesis Intra-abdominal or visceral obesity is associated with insulin resistance and an increased risk for cardiovascular disease. This study aimed to compare the effects of semaglutide $1.0 \mathrm{mg}$ and canagliflozin $300 \mathrm{mg}$ on body composition in a subset of participants from the SUSTAIN 8 Phase IIIB, randomised double-blind trial who underwent whole-body dual-energy $\mathrm{X}$-ray absorptiometry (DXA) scanning.

Methods Adults (age $\geq 18$ years) with type 2 diabetes, $\mathrm{HbA}_{1 \mathrm{c}} 53-91 \mathrm{mmol} / \mathrm{mol}(7.0-10.5 \%$ ), on a stable daily dose of metformin ( $\geq 1500 \mathrm{mg}$ or maximum tolerated dose) and with an eGFR $\geq 60 \mathrm{ml} \mathrm{min}{ }^{-1}[1.73 \mathrm{~m}]^{-2}$ were randomised 1:1 to semaglutide $1.0 \mathrm{mg}$ once weekly and canagliflozin placebo once daily, or canagliflozin $300 \mathrm{mg}$ once daily and semaglutide placebo once weekly. Body composition was assessed using whole-body DXA scans. The study participants and investigator remained blinded throughout the trial, and quality of DXA scans was evaluated in a blinded manner. Change from baseline to week 52 in total fat mass $(\mathrm{kg})$ was the confirmatory efficacy endpoint.

Results A subset of 178 participants (semaglutide, $n=88$; canagliflozin, $n=90$ ) underwent DXA scanning at screening and were randomised into the substudy. Of these, 114 (semaglutide, $n=53$; canagliflozin, $n=61$ ) participants had observed end-of-treatment data included in the confirmatory efficacy analysis. Of the 178 participants in the substudy, numerical improvements in body composition (including fat mass, lean mass and visceral fat mass) were observed after 52 weeks with both treatments. Total fat mass (baseline $33.2 \mathrm{~kg}$ ) was reduced by $3.4 \mathrm{~kg}$ and $2.6 \mathrm{~kg}$ with semaglutide and canagliflozin, respectively (estimated treatment difference: 0.79 [95\% CI - 2.10, 0.51]). Although total lean mass (baseline $51.3 \mathrm{~kg}$ ) was also reduced by $2.3 \mathrm{~kg}$ and $1.5 \mathrm{~kg}$ with semaglutide and canagliflozin, respectively (estimated treatment difference: $-0.78[-1.61,0.04]$ ), the proportion of lean mass (baseline $59.4 \%$ ) increased by $1.2 \%$ - and $1.1 \%$-point, respectively (estimated treatment difference $0.14[-0.89,1.17])$. Changes in visceral fat mass and overall changes in body composition (assessed by the fat to lean mass ratio) were comparable between the two treatment groups.

Conclusions/interpretation In individuals with uncontrolled type 2 diabetes on stable-dose metformin therapy, the changes in body composition with semaglutide and canagliflozin were not significantly different. Although numerical improvements in body composition were observed following treatment in both treatment arms, the specific impact of both treatments on body composition in the absence of a placebo arm is speculative at this stage.
\end{abstract}

Trial registration ClinicalTrials.gov NCT03136484.

Funding This trial was supported by Novo Nordisk A/S, Denmark.

Keywords Body composition · Canagliflozin · Fat mass · Glucagon-like peptide receptor agonists $\cdot$ Randomised controlled trial $\cdot$ Semaglutide · Type 2 diabetes · Weight

Rory J. McCrimmon

r.mccrimmon@dundee.ac.uk

1 School of Medicine, University of Dundee, Ninewells Hospital and Medical School, Dundee DD1 9SY, UK

2 Novo Nordisk A/S, Vandtårnsvej, Søborg, Denmark
3 National Research Institute, Los Angeles, CA, USA

4 Diabetes Complications Research Centre, University College Dublin, Dublin, Ireland

5 Department of Internal Medicine, UT Southwestern Medical Center, Dallas, TX, USA 


\section{Research in context}

What is already known about this subject?

- The link between obesity and type 2 diabetes is well established, and visceral obesity is associated with insulin resistance and increased cardiovascular risk

- Many conventional glucose-lowering therapies are associated with weight gain

- Phase III trials have shown that glucagon-like peptide-1 receptor agonists (GLP-1RAs) and sodium-glucose cotransporter-2 inhibitors (SGLT-2is) induce clinically meaningful weight loss in individuals with type 2 diabetes

What is the key question?

- Is the weight reduction associated with semaglutide, a GLP-1RA, and canagliflozin, an SGLT-2i, comparable in terms of body composition as measured by whole-body dual-energy $\mathrm{x}$-ray absorptiometry scanning?

What are the new findings?

- Numerical reductions in total fat mass and visceral fat mass were observed in each treatment arm

- Changes in body composition were not statistically different between treatments

How might this impact on clinical practice in the foreseeable future?

- There is no evidence that changes in body composition between semaglutide and canagliflozin in individuals with type 2 diabetes are significantly different. Although numerical improvements were seen with both a GLP-1RA and SGLT-2i, this study highlights the need for further research into the specific effects of treatments in both classes on components of body composition in the presence of a placebo arm

\section{Abbreviations \\ DXA Dual-energy x-ray absorptiometry \\ ETD Estimated treatment difference \\ GLP-1RA Glucagon-like peptide-1 receptor agonist \\ SGLT-2i Sodium-glucose co-transporter-2 inhibitor \\ SUSTAIN Semaglutide Unabated Sustainability in Treatment of Type 2 Diabetes}

\section{Introduction}

The association between obesity and type 2 diabetes is well established $[1,2]$. Intra-abdominal or visceral obesity in particular is associated with insulin resistance [3, 4] and an increased risk for developing cardiovascular disease $[4,5]$. In addition to providing recommendations for achieving glycaemic control, current type 2 diabetes guidelines emphasise the importance of weight loss through lifestyle changes, surgical interventions or medications $[6,7]$. While some conventional glucose-lowering medications contribute to weight gain [2], newer agents - including those from the glucagon-like peptide-1 receptor agonist (GLP-1RA) and sodium-glucose co-transporter-2 inhibitor (SGLT-2i) classes have favourable effects on body weight [2]. This is an important feature, because weight gain can lead to non-compliance with therapy [8].

Semaglutide is a GLP-1RA approved for the subcutaneous, once-weekly treatment of type 2 diabetes $[9,10]$. The efficacy and safety of once-weekly semaglutide have been established in the
SUSTAIN (Semaglutide Unabated Sustainability in Treatment of Type 2 Diabetes) clinical trial programme across the continuum of care in individuals with type 2 diabetes vs placebo and a range of comparators (SUSTAIN 1-5 and 7-10) [11-19] and in a cardiovascular outcomes trial (SUSTAIN 6) [20]. Canagliflozin is an SGLT-2i approved for the oral, once-daily treatment of type 2 diabetes [21]. The efficacy and safety of canagliflozin $100 \mathrm{mg}$ and $300 \mathrm{mg}$ have been demonstrated in an extensive clinical development programme that included cardiovascular and renal outcomes trials (CANVAS, CANVAS-R and CREDENCE) [22, 23]. Both semaglutide and canagliflozin are associated with substantial reductions in body weight. Across the SUSTAIN 110 trials, semaglutide has demonstrated significantly greater weight loss vs all comparators, with absolute change in body weight ranging from -3.8 to $-6.5 \mathrm{~kg}$ with semaglutide $1.0 \mathrm{mg}$ [11-20]. Canagliflozin has consistently demonstrated weight reductions of 2.5 to $4.7 \mathrm{~kg}$ in clinical trials [24].

Recently, a Phase IIIB randomised double-blind trial (SUSTAIN 8) compared the effects of once-weekly semaglutide $1.0 \mathrm{mg}$ vs once-daily canagliflozin $300 \mathrm{mg}$ on glycaemic control and weight management in participants with uncontrolled type 2 diabetes on a background of metformin therapy [17]. Treatment with semaglutide resulted in a mean change in $\mathrm{HbA}_{1 \mathrm{c}}$ from baseline to week 52 of $-16.2 \mathrm{mmol} / \mathrm{mol}(-1.5 \%$-point $)$ compared with $-10.4 \mathrm{mmol} / \mathrm{mol}(-1.0 \%$-point) for canagliflozin $(p<0.0001)$, and a weight loss of $-5.3 \mathrm{~kg}$ vs $-4.2 \mathrm{~kg}$, respectively $(p=0.003)$. 
The magnitude of weight loss demonstrated in the SUSTAIN 8 trial would be expected to result in positive changes in body composition; however, as with any glucoselowering agent, it is important to evaluate whether this weight loss has an adverse impact on the ratio of fat to lean mass.

To date, whether the effects on weight loss associated with the GLP-1RA semaglutide, and the SGLT-2i canagliflozin, are comparable in terms of total, lean and visceral fat have not yet been evaluated. This study compared body composition components in a subset of participants from SUSTAIN 8 who received semaglutide $1.0 \mathrm{mg}$ or canagliflozin $300 \mathrm{mg}$ using whole-body dual-energy $\mathrm{x}$-ray absorptiometry (DXA).

\section{Methods}

\section{SUSTAIN 8 study design}

Trial design and participants The trial design for SUSTAIN 8 (ClinicalTrials.gov registration no. NCT03136484) has been described previously [17]. Briefly, SUSTAIN 8 was a 52week, Phase IIIB randomised double-blind, double-dummy, parallel-group trial of once-weekly semaglutide $1.0 \mathrm{mg}$ vs once-daily canagliflozin $300 \mathrm{mg}$ in 788 adults with type 2 diabetes on stable treatment with metformin. The trial was conducted at 111 centres in 11 countries. Adults (age $\geq 18$ years) with uncontrolled type 2 diabetes, $\mathrm{HbA}_{1 \mathrm{c}}$ levels of 53-91 $\mathrm{mmol} / \mathrm{mol}(7.0-10.5 \%$ [inclusive]) on a stable daily dose of metformin ( $\geq 1500 \mathrm{mg}$ or maximum tolerated dose) for at least 90 days prior to screening and an eGFR $\geq 60 \mathrm{ml} \mathrm{min}^{-1}$ $[1.73 \mathrm{~m}]^{-2}$ were eligible. Individuals with a history or presence of pancreatitis (acute or chronic), history of diabetic ketoacidosis, myocardial infarction, stroke, hospitalisation for unstable angina or transient ischaemic attack within 180 days prior to screening, and New York Heart Association class IV heart failure were excluded.

Randomisation and treatment Participants were randomised in a 1:1 manner to receive either once-weekly semaglutide $1.0 \mathrm{mg}$ subcutaneous injections and once-daily canagliflozin placebo oral tablets, or once-daily canagliflozin $300 \mathrm{mg}$ oral tablets and once-weekly subcutaneous semaglutide placebo. Randomisation was stratified according to participation in the substudy (yes/no) to ensure balanced treatment allocation. Dosing for semaglutide began at $0.25 \mathrm{mg}$ and doubled every 4 weeks until the maintenance dose of $1.0 \mathrm{mg}$ was achieved at 8 weeks. Participants randomised to canagliflozin received $100 \mathrm{mg}$ for 8 weeks, followed by an increase to the maintenance dose of $300 \mathrm{mg}$. The only background medication permitted was metformin $(\geq 1500 \mathrm{mg}$ or maximum tolerated dose). Participants continued on their pre-trial dose throughout the treatment period unless rescue medication was required. After a treatment period of 52 weeks, participants entered a 5-week follow-up period.

Outcomes The primary and confirmatory secondary endpoints were change from baseline to week 52 in $\mathrm{HbA}_{1 \mathrm{c}}$ (\%-point) and body weight $(\mathrm{kg})$, respectively.

Ethics and consent SUSTAIN 8 was conducted in compliance with the International Conference on Harmonisation Good Clinical Practice guidelines [25] and the Declaration of Helsinki [26]. The trial protocol was approved by the institutional review board and ethics committee at each participating centre, and participants provided written informed consent before trial-related activities commenced.

\section{DXA substudy}

A planned subset of participants from the overall SUSTAIN 8 population received a DXA whole-body scan at baseline and were randomised for inclusion in the body composition substudy if the imaging laboratory deemed the quality of the scan to be acceptable.

Assessments and outcomes The process of DXA scan image acquisition, transfer, central analysis, reporting of results and arching followed the charter prepared by one imaging laboratory (PAREXEL Informatics Medical Imaging, Waltham, MA, USA) where scans were analysed. GE Lunar iDXA (GE Healthcare, Madison, WI, USA) and the Hologic Discovery DXA system (Hologic, Marlborough, MA, USA) were used with Prodigy and APEX software, respectively. Each participant received one scan 5 days after the screening (visit 1) and a second, final scan 5 days after the end-oftreatment visit (planned study end or premature treatment discontinuation). The quality of the DXA scans was evaluated by the same imaging laboratory in a blinded manner.

Change from baseline to week 52 in total fat mass $(\mathrm{kg})$ was the confirmatory efficacy endpoint in the DXA substudy. Changes from baseline to week 52 in total fat mass (\%-point), total lean mass ( $\mathrm{kg}$ and \%-point), visceral fat mass ( $\mathrm{kg}$ and \%point) and ratio of total fat mass to total lean mass (muscle mass in this study) were additional efficacy endpoints. A comparison of change in body weight within the substudy vs the primary study was performed post hoc in order to confirm that weight loss in individuals undergoing a DXA scan in the substudy was representative of the weight loss in the primary study.

Statistical analyses The primary estimand was defined as the treatment difference between semaglutide and canagliflozin at week 52 for all randomised participants if all participants completed treatment and did not start rescue medication. The primary estimand was used to estimate the expected benefit from the initiation and continuation of semaglutide 
compared with canagliflozin, drawing inferences only from data collected before discontinuation of trial product or initiation of rescue medication. The estimand was based on the full analysis set of all randomised participants using post-baseline measurements up to and including week 52 from the 'ontreatment without rescue medication' observation period to support an efficacy evaluation. The analysis of all endpoints in the substudy was based on the subset of full analysis set participants who participated in the substudy (DXA analysis set); however, participants had only two DXA scans each, and not all of these were performed within the 'on-treatment without rescue medication' observation period (used for the confirmatory analysis). In individuals for whom DXA data were collected outside of this period, only baseline data were included in the analysis, and the corresponding end-oftreatment data were multiple imputed, as described below.

An ANCOVA with treatment and region as categorical effects and baseline measurements as a covariate was used to analyse values at week 52 , and change from baseline estimates were adjusted according to the pooled baseline value to allow for comparison between treatment arms. Before analysis, missing data were imputed using observed data from participants within the same treatment group, using a regression model including region as categorical effect and baseline value as covariate. Rubin's rules were used to combine the analysis results to draw inference [27]. Regions were defined as North America (USA and Canada); Region Europe (UK, Ireland and Sweden); or International Operations (Lebanon, Malaysia, Argentina, Mexico, Brazil and India).

As a confirmatory endpoint, change in total fat mass $(\mathrm{kg})$ was tested for superiority of semaglutide $1.0 \mathrm{mg}$ vs canagliflozin $300 \mathrm{mg}$. The overall type I error for the confirmatory hypotheses in SUSTAIN 8 and the substudy were controlled at a 5\% level (two-sided) using a closed testing procedure (Fig. 1) [28]. Assuming a treatment difference of $1.8 \mathrm{~kg}$ and $\mathrm{SD}$ of $3.5 \mathrm{~kg}$, it was estimated that 174 participants ( 87 per arm) would provide a $92 \%$ marginal power to establish a significant difference, resulting in $91 \%$ power for confirming superiority in the testing strategy for total fat mass loss $(\mathrm{kg})$ at week 52 .

Sensitivity analyses to evaluate the robustness of the conclusions from the confirmatory analysis (change in total fat mass $[\mathrm{kg}]$ ) included a pre-specified in-trial analysis using all post-baseline measurements up to and including week 52 from the in-trial observation period, in which participants were considered to be in the trial after randomisation regardless of discontinuation of trial product or initiation of rescue medication. Scans that did not meet the criteria for inclusion in the confirmatory analysis (performed $>7$ days after last dose of trial product and thus considered out-of-window, or taken after initiation of rescue medication) were included in the intrial supplementary analysis. Data from missing scans were multiple imputed.
In post hoc analyses, possible correlations between fat loss and changes in body weight, $\mathrm{HbA}_{1 \mathrm{c}}$ and $\mathrm{BP}$ were investigated. Correlations were calculated for each of the 500 complete multiple imputed datasets for body weight, $\mathrm{HbA}_{1 \mathrm{c}}$ and systolic and diastolic BP and combined using Rubin's rules [27].

\section{Results}

Between 15 March 2017 and 16 November 2018, 788 individuals were randomised to receive semaglutide $1.0 \mathrm{mg}$ or canagliflozin $300 \mathrm{mg}$ (each $n=394$ ). A subset of 178 participants (semaglutide, $n=88$; canagliflozin, $n=90$ ) underwent DXA scanning at screening and were also randomised into the SUSTAIN 8 substudy. Of these, 177 (99.4\%) participants (semaglutide, $n=87$; canagliflozin, $n=90$ ) were exposed to treatment. In total, $25(14.0 \%)$ participants discontinued treatment prematurely, primarily because of adverse events $(n=8$ [4.5\%]). Overall, 165 of 178 participants $(92.7 \%)$ had a postbaseline DXA scan available (Table 1; Fig. 2). Of these, data on 114 (64\%: semaglutide, $n=53$ [60.2\%]; canagliflozin, $n=$ $61[67.8 \%]$ ) were within the on-treatment without rescue medication period and used in the confirmatory efficacy analysis (Table 1; Fig. 2). The remaining post-baseline DXA scan results were excluded from the confirmatory analysis because scans at discontinuation were performed $>7$ days after the last dose of trial product (i.e. out-of-window; $n=38$ ) or participants were on rescue medication at the time of the scan $(n=$ 13). The pre-specified in-trial analysis used all post-baseline measurements up to and including week 52 from the in-trial observation period, i.e. all 165 available post-baseline scans (including out-of-window scans and scans of participants on rescue medication).

\section{Baseline characteristics}

Baseline characteristics were comparable between treatment arms (Table 1). Participants had an overall mean (SD) baseline $\mathrm{HbA}_{1 \mathrm{c}}$ value of $68.0 \mathrm{mmol} / \mathrm{mol}$ (11.5) [8.4\% (1.0)] and body weight of $88.3 \mathrm{~kg}$ (18.2). Overall mean (SD) baseline body composition values were $33.2 \mathrm{~kg} \mathrm{(11.0)} \mathrm{and} 37.6 \%$ (7.8) for total fat mass, $51.3 \mathrm{~kg}(10.4)$ and $59.4 \%$ (7.5) for total lean mass, and $1.5 \mathrm{~kg}(0.8)$ (representing 43.9\% [15.7] of abdominal fat) for visceral fat mass. The overall mean (SD) baseline total fat mass to total lean mass ratio was $0.7(0.2)$.

\section{Change in total fat mass}

Numerical reductions in fat mass ( $\mathrm{kg}$ and \%-point) were observed with both treatments. Estimated reductions were numerically greater for semaglutide vs canagliflozin, but the differences were not statistically significant (Fig. 3a, b). Total fat mass (SE) was reduced with semaglutide and canagliflozin 


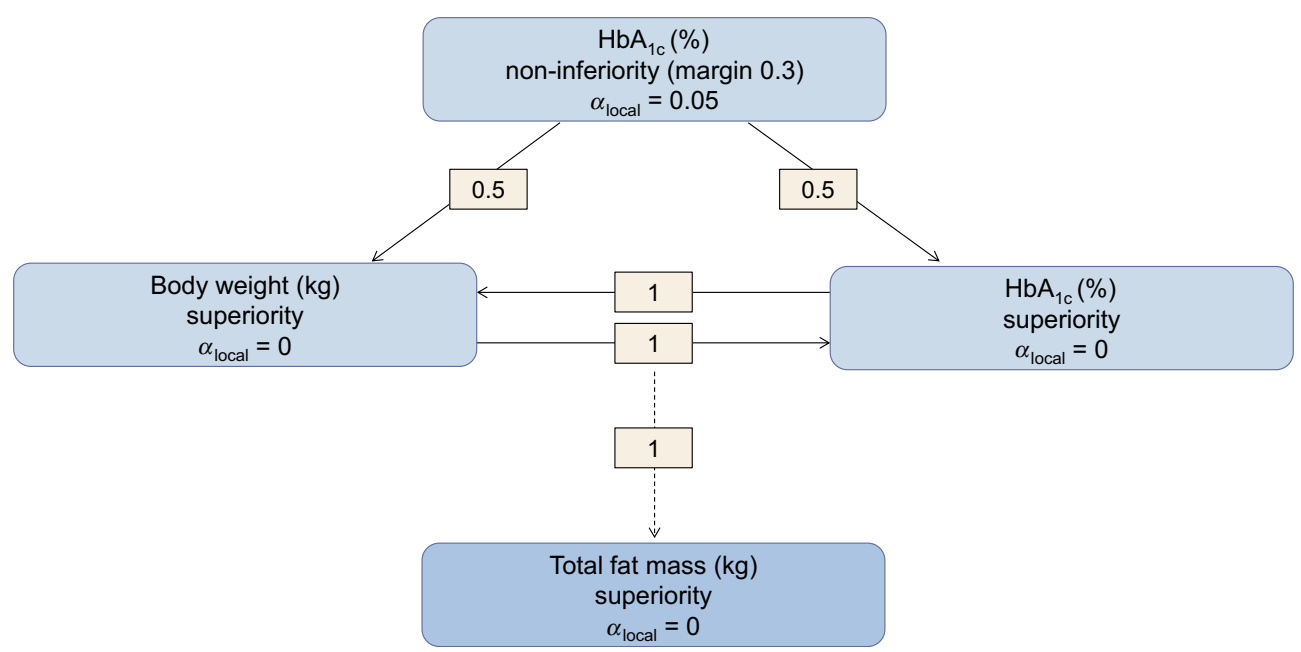

Fig. 1 Graphical illustration of the closed testing procedure. The overall significance level of $\alpha=0.05$ (two-sided) is initially allocated to the $\mathrm{HbA}_{1 \mathrm{c}}$ non-inferiority test. The local significance level $\left(\alpha_{\text {local }}\right)$ will be reallocated if a hypothesis is confirmed according to the weight given by the directed edges between nodes (hypotheses). The total fat-mass superiority test will receive the overall significance of $\alpha=0.05$ (twosided) if, and only if, both $\mathrm{HbA}_{1 \mathrm{c}}$ and body weight superiority are confirmed at their respective local significance levels from an overall baseline of $33.2 \mathrm{~kg}: 3.4 \mathrm{~kg}(0.51)$ vs $2.6 \mathrm{~kg}$ (0.45), respectively (Fig. 3a), with an estimated treatment difference (ETD; 95\% CI) of $-0.79(-2.10,0.51)$. The supplementary in-trial analysis of all available data demonstrated similar, non-significant results for total fat mass with reductions of $3.0 \mathrm{~kg}(0.37)$ and $2.3 \mathrm{~kg}(0.36)$ for semaglutide and canagliflozin, respectively (ETD -0.71 [95\% CI -1.72, 0.31]).

The proportion of total fat mass (SE) was reduced from an overall baseline of $37.6 \%$ by $1.4 \%$-point $(0.39)$ and $1.2 \%$ point $(0.35)$ with semaglutide and canagliflozin, respectively (ETD -0.21 [95\% CI -1.26, 0.84]) (Fig. 3b). Cumulative changes in total fat mass were comparable between semaglutide and canagliflozin; over 52 weeks, approximately $80 \%$ of participants experienced reduced total fat mass with both treatments (Fig. 3h).

Post hoc correlation coefficient analysis A moderate correlation was observed between change in total fat mass and change in body weight between baseline and week 52 for semaglutide $(r=0.61$ [95\% CI 0.40, 0.76]) and canagliflozin $(r=0.54[0.32,0.70])$ (Fig. 4a). There were no correlations between change in total fat mass and change in $\mathrm{HbA}_{1 \mathrm{c}}$, systolic BP or diastolic BP over the same period with either semaglutide or canagliflozin $(r=0.01-0.20)$ (Fig. $4 b-d)$.

\section{Change in total lean mass}

Total lean mass (SE) was reduced from an overall baseline of $51.3 \mathrm{~kg}$ by $2.3 \mathrm{~kg}(0.30)$ vs $1.5 \mathrm{~kg}(0.28)$ in the semaglutide and canagliflozin treatment groups, respectively (ETD -0.78 [95\% CI -1.61, 0.04]) (Fig. 3c). In contrast, lean mass as a proportion of the whole (SE) increased from an overall baseline of $59.4 \%$ by $1.2 \%$-point $(0.39)$ with semaglutide vs $1.1 \%$ - point $(0.34)$ with canagliflozin (ETD $0.14[-0.89,1.17])$ (Fig. 3d).

\section{Change in visceral fat mass}

The decreases in visceral fat mass (SE) were $0.2 \mathrm{~kg}(0.05)$ and $0.1 \mathrm{~kg}(0.04)$ with semaglutide and canagliflozin, respectively (ETD -0.07 [95\% CI -0.20, 0.06]) (Fig. 3e). The percentage of visceral fat mass (SE) decreased from an overall baseline mean of $43.9 \%$ by $0.9 \%$-point ( 0.94$)$ with semaglutide vs an increase of $0.4 \%$-point $(0.69)$ with canagliflozin (ETD -1.38 $[-3.65,0.88])$ (Fig. 3f).

\section{Ratio between total fat mass and total lean mass}

Body composition changes, as assessed by the fat to lean mass ratio (SE), were favourable for both treatment groups: -0.04 $(0.01)$ and $-0.03(0.01)$ with semaglutide and canagliflozin, respectively (ETD -0.01 [95\% CI -0.04, 0.02]) (Fig. 3g).

\section{Change in body weight}

In a post hoc calculation of the substudy cohort $(n=178)$, which served to illustrate consistency between weight loss in participants undergoing a DXA scan in the substudy and in the primary study, reduction in total fat plus lean mass was $5.7 \mathrm{~kg}$ with semaglutide vs $4.1 \mathrm{~kg}$ with canagliflozin in the substudy, suggesting a weight-loss pattern similar to that observed between treatments in the whole SUSTAIN 8 population (Table 2). Moreover, the distribution of body weight loss was similar in the SUSTAIN 8 substudy compared with the main SUSTAIN 8 trial in participants receiving both semaglutide and canagliflozin (Fig. 5a, b, respectively). 
Table 1 Body composition substudy participant disposition and baseline characteristics

\begin{tabular}{|c|c|c|c|}
\hline Variable & $\begin{array}{l}\text { Semaglutide } \\
1.0 \mathrm{mg}(n=88)\end{array}$ & $\begin{array}{l}\text { Canagliflozin } \\
300 \mathrm{mg}(n=90)\end{array}$ & Total $(n=178)$ \\
\hline \multicolumn{4}{|l|}{ Participant disposition, $n(\%)$} \\
\hline Randomised, DXA & $88(100)$ & $90(100)$ & $178(100)$ \\
\hline Exposed & $87(98.9)$ & $90(100)$ & $177(99.4)$ \\
\hline Observed EOT scan in in-trial analysis ${ }^{\mathrm{a}}$ & $82(93.2)$ & $83(92.2)$ & $165(92.7)$ \\
\hline Observed EOT scan in confirmatory analysis ${ }^{\mathrm{b}}$ & $53(60.2)$ & $61(67.8)$ & $114(64.0)$ \\
\hline Treatment completers $^{c}$ & $76(86.4)$ & $76(84.4)$ & $152(85.4)$ \\
\hline Without rescue medication & $63(71.6)$ & $69(76.7)$ & $132(74.2)$ \\
\hline Premature treatment discontinuation ${ }^{\mathrm{d}}$ & $11(12.5)$ & $14(15.6)$ & $25(14.0)$ \\
\hline Adverse events & $6(6.8)$ & $2(2.2)$ & $8(4.5)$ \\
\hline Lost to follow-up & $1(1.1)$ & $2(2.2)$ & $3(1.7)$ \\
\hline Other & $4(4.5)$ & $10(11.1)$ & $14(7.9)$ \\
\hline Trial completers ${ }^{\mathrm{e}}$ & $80(90.9)$ & $81(90.0)$ & $161(90.4)$ \\
\hline \multicolumn{4}{|c|}{ Demographics and baseline characteristics, mean (SD) } \\
\hline Age, years & $57.8(9.9)$ & $58.6(10.1)$ & $58.2(10.0)$ \\
\hline $\mathrm{HbA}_{1 \mathrm{c}}, \mathrm{mmol} / \mathrm{mol}$ & $69.4(11.9)$ & $66.7(10.9)$ & $68.0(11.5)$ \\
\hline $\mathrm{HbA}_{1 \mathrm{c}}, \%$ & $8.5(1.1)$ & $8.3(1.0)$ & $8.4(1.0)$ \\
\hline Diabetes duration, years & $8.8(5.8)$ & $8.5(5.2)$ & $8.7(5.5)$ \\
\hline Body weight, $\mathrm{kg}$ & $89.0(18.2)$ & $87.6(18.2)$ & $88.3(18.2)$ \\
\hline BMI, $\mathrm{kg} / \mathrm{m}^{2}$ & $32.6(6.4)$ & $32.3(5.5)$ & $32.4(6.0)$ \\
\hline Waist circumference, $\mathrm{cm}$ & $104.0(13.5)$ & $105.9(13.1)$ & $105.0(13.3)$ \\
\hline \multicolumn{4}{|l|}{ Total fat mass, } \\
\hline $\mathrm{kg}$ & $33.9(11.9)$ & $32.5(10.0)$ & $33.2(11.0)$ \\
\hline$\%$ & $38.0(8.4)$ & $37.3(7.3)$ & $37.6(7.8)$ \\
\hline \multicolumn{4}{|l|}{ Total lean mass, } \\
\hline $\mathrm{kg}$ & $51.3(10.1)$ & $51.3(10.7)$ & $51.3(10.4)$ \\
\hline$\%$ & $59.1(8.0)$ & $59.7(6.9)$ & $59.4(7.5)$ \\
\hline \multicolumn{4}{|l|}{ Visceral fat mass, } \\
\hline $\mathrm{kg}$ & $1.5(0.8)$ & $1.5(0.8)$ & $1.5(0.8)$ \\
\hline$\%$ & $43.7(16.2)$ & $44.0(15.3)$ & $43.9(15.7)$ \\
\hline Total fat mass:total lean mass ratio & $0.67(0.23)$ & $0.65(0.20)$ & $0.66(0.22)$ \\
\hline
\end{tabular}

The baseline value is defined as the latest pre-dosing value

${ }^{\text {a }}$ Participants with end-of-treatment data included in the pre-specified supplementary analysis

${ }^{\mathrm{b}}$ Participants with end-of-treatment data included in the pre-specified confirmatory analyses

${ }^{\mathrm{c}}$ Participants who completed treatment according to the end-of-treatment form

${ }^{\mathrm{d}}$ Includes only exposed participants

${ }^{\mathrm{e}}$ Participants who completed the trial according to the end-of-trial form

EOT, end-of-treatment (planned or premature)

\section{Discussion}

In the SUSTAIN 8 substudy, numerical reductions in absolute and proportion of total fat mass were observed for treatment with both semaglutide $1.0 \mathrm{mg}$ and canagliflozin $300 \mathrm{mg}$. Although fat loss was numerically greater with semaglutide vs canagliflozin after 52 weeks of treatment, the difference was not statistically significant. Overall, $36 \%$ of participants were missing DXA scans for the end-of-treatment confirmatory analysis, mainly because scans were taken out-of-window
( $>7$ days after the last dose of trial product). However, the supplementary in-trial analysis of all available scans demonstrated similar results, supporting the robustness of the conclusion for this endpoint. Numerical reductions were observed in both treatment groups in absolute lean mass $(\mathrm{kg})$, although an increase in the proportion of total lean mass (\%-point) was observed. However, the change in ratio between total fat mass and total lean mass was minimal in both treatment groups, and was not significantly different between groups. A marginal decrease in absolute visceral fat mass was observed with both 


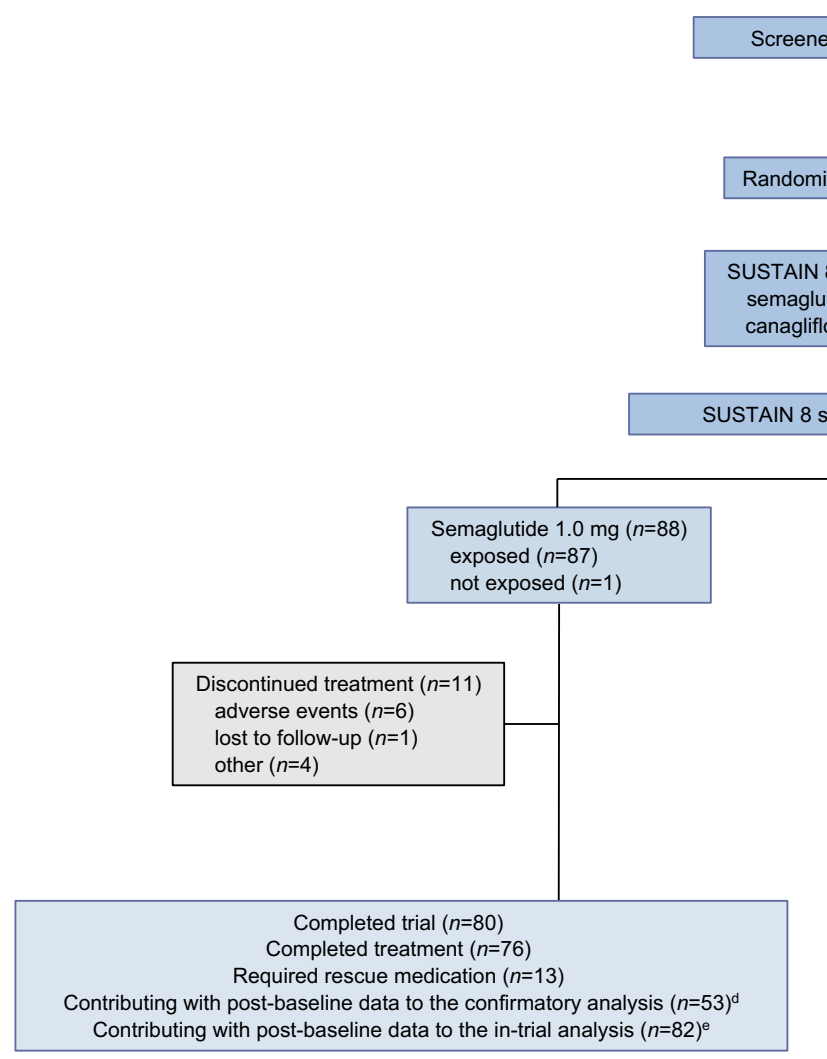

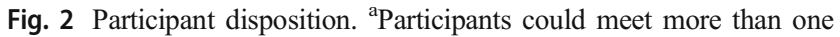
exclusion criterion. ' 'Not assigned' includes individuals who withdrew consent before randomisation. ${ }^{\mathrm{C}}$ Participants in the substudy were a subset of the overall SUSTAIN 8 trial population. ${ }^{\mathrm{d}}$ In participants for whom data

treatments, whereas the proportion of visceral fat decreased slightly with semaglutide and increased slightly with canagliflozin, although differences between treatment arms were not significant. Importantly, in this substudy, there was no evidence of deleterious body composition changes, such as reductions in proportion of total lean mass; although the specific impact of both treatments on body composition in the absence of a placebo arm is speculative at this stage.

DXA, a two-compartment method of body composition analysis that separates body components into fat mass and fat-free mass, is one of the most popular and widely used non-invasive techniques for estimating whole-body and regional body composition [29]. When used in relation to body composition, the term 'lean mass' usually refers to muscle mass; however, lean mass comprises the combined weight of internal organs, muscle, connective tissue and water. It is important to consider the influence of these non-muscle components in DXA measurements of lean mass, and particularly the inability of DXA to calculate variable amounts of water [29], making it difficult to distinguish between loss of muscle and reduction in extracellular volume.

The link between obesity and type 2 diabetes is well known $[1,2]$. Abdominal obesity is a key factor in the development of

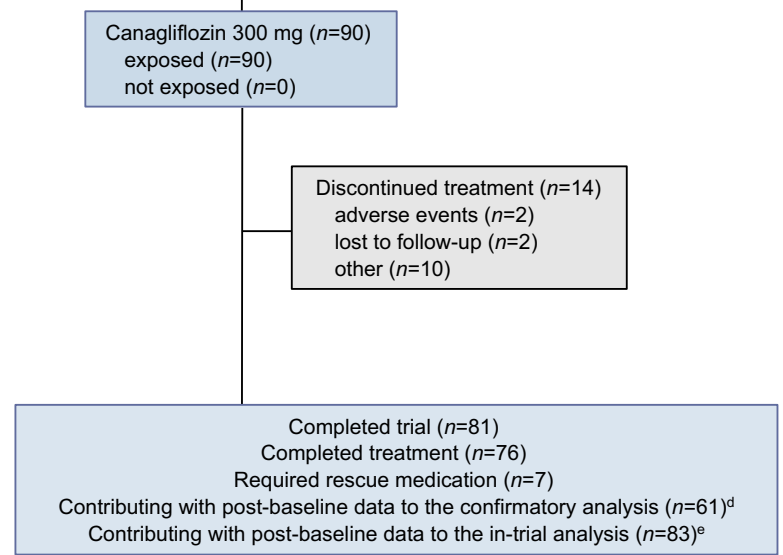

were outside the relevant observation period, only baseline participant data were included in the analysis, and the corresponding end-of-treatment data were multiple imputed. ${ }^{\mathrm{e}}$ The in-trial analysis included all available post-baseline data. Missing data were multiple imputed

diabetes and cardiovascular disease [30] and is a risk factor for several chronic diseases with cardiometabolic homeostasis [31]. Recent studies showing reduction in visceral fat in normal-weight [31] and overweight individuals [32] may have implications with regard to improving cardiometabolic profile. Although many conventional glucose-lowering therapies may contribute to weight gain, treatment with GLP-1RAs and SGLT-2is has been associated with clinically meaningful weight loss [2]. In SUSTAIN 8, treatment with semaglutide and canagliflozin resulted in substantial weight loss of $-5.3 \mathrm{~kg}$ and $-4.2 \mathrm{~kg}$, respectively (ETD -1.06 [95\% CI $1.76,-0.36] ; p=0.003$ favouring semaglutide), with more participants in the semaglutide arm achieving weight loss $\geq 10 \%$ than those in the canagliflozin arm $(22.3 \%$ vs $8.9 \%$; OR 2.99 [95\% CI 1.89, 4.75]; $p<0.0001$ ). A post hoc calculation of reduction in overall mass (fat mass plus lean body mass) in the DXA substudy indicated reductions of $5.7 \mathrm{~kg}$ vs $4.1 \mathrm{~kg}$ for semaglutide and canagliflozin, respectively. The distribution of body weight loss in participants in the SUSTAIN 8 substudy receiving semaglutide and canagliflozin was similar compared with all participants in the primary SUSTAIN 8 trial.

The magnitude of weight loss may have implications for the effect of treatment on lean muscle mass. Regular diet- 
Fig. 3 Body composition outcomes after 52 weeks of treatment. Change from baseline in total fat mass: $\mathrm{kg} \mathrm{(a)} \mathrm{and} \mathrm{\%} \mathrm{(b);}$ total lean mass: $\mathrm{kg}(\mathbf{c})$ and $\%(\mathbf{d})$; visceral fat mass: $\operatorname{kg}(\mathbf{e})$ and \% (f); ratio of total fat mass to total lean mass (g); and cumulative change in total fat mass (h). 'Ontreatment without rescue medication' data ( $n=114$ [semaglutide, $n=53$; canagliflozin, $n=61]$ ). Missing data were multiple imputed using observed data from participants within the same group defined by randomised treatment, using a regression model including region as categorical effect and data from baseline as covariate. $(\mathbf{a}-\mathbf{g})$

Responses were analysed using an ANCOVA with treatment and region as fixed factors and baseline value as covariate. Regions were defined as North America (USA and Canada); Region Europe (UK, Ireland and Sweden); or International Operations (Lebanon, Malaysia, Argentina, Mexico, Brazil and India). Numbers on the bars may not match the numbers on the scale due to rounding. (h) The dashed line on the $y$-axis shows the 50 th percentile, while the dashed line on the $x$-axis shows the reference value for no change
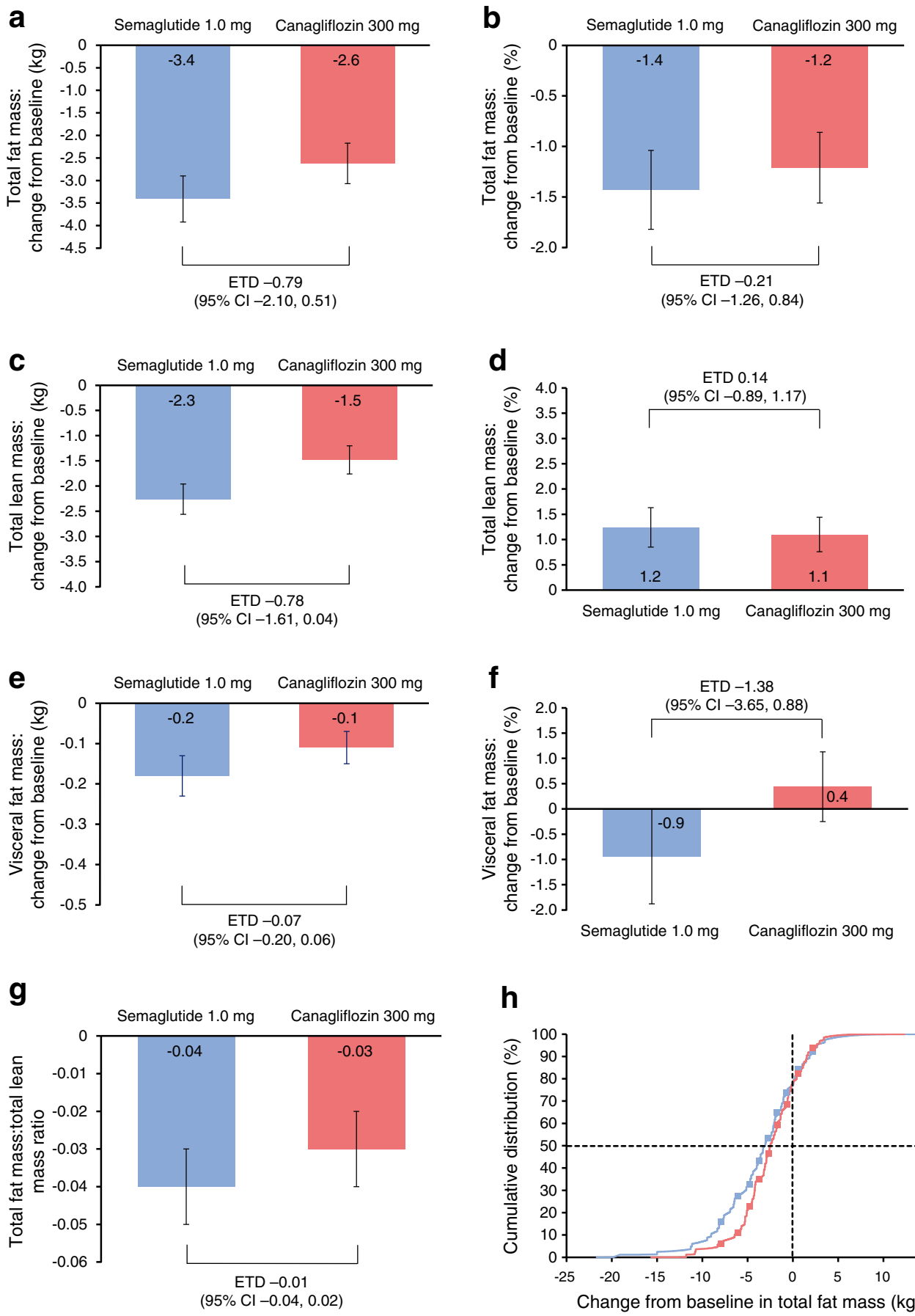

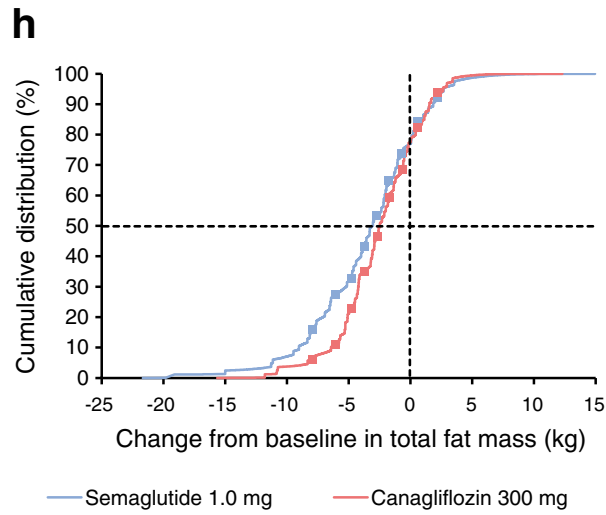

induced weight loss is associated with corresponding changes in both body fat and fat-free mass, including muscle [33]. In individuals with type 2 diabetes, it is preferable to reduce fat without significant loss of lean mass [32], although this can occur during weight loss in those who are obese [34]. Because skeletal muscle is the major site of postprandial glucose uptake [35], a decrease in lean mass may be associated with impaired glucose metabolism in individuals with type 2 diabetes. However, this is a complex process for which there are various contributing factors. A recent trial examining the effect of the SGLT-2i ipragliflozin in Japanese people with obesity revealed similar mean reductions of fat mass and total lean mass of $1.8 \mathrm{~kg}$ and $1.7 \mathrm{~kg}$, respectively, including a small but significant $0.6 \mathrm{~kg}$ loss in appendicular lean mass (a good marker of skeletal muscle mass), suggesting that SGLT-2is may induce catabolism of both body fat and muscle secondary to glycosuria [36]. However, the use of DXA for the estimation of changes in body composition in SGLT-2i trials has 

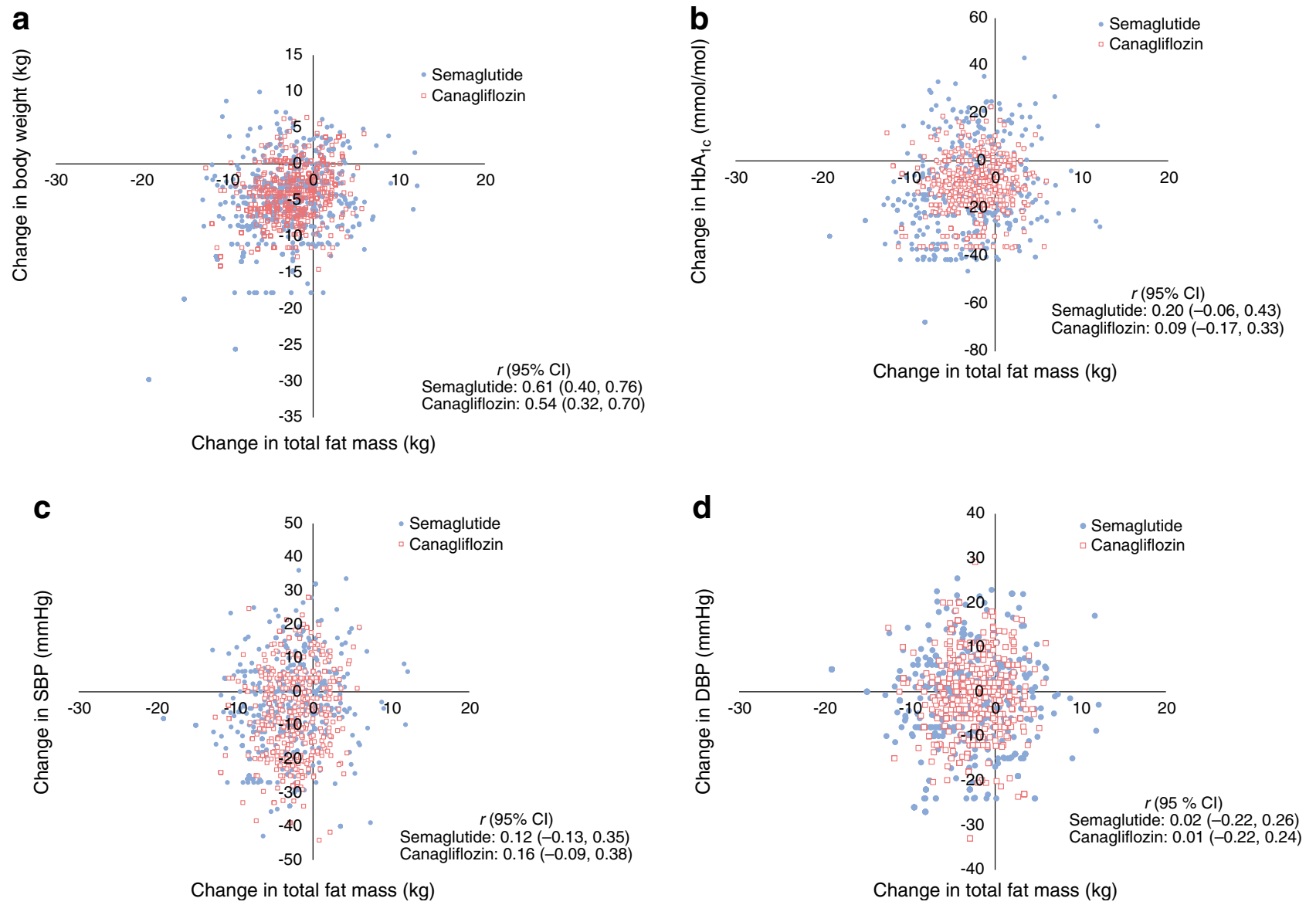

Fig. 4 Correlation of absolute change in total fat mass $(\mathrm{kg})$ with change in body weight (a), $\mathrm{HbA}_{1 \mathrm{c}}$ (b), SBP (c) and DBP (d) after 52 weeks of treatment. Each point represents data (observed or imputed) from one participant. 'On-treatment without rescue medication' data for all randomised participants

demonstrated greater reductions in fat mass $(2.2$ to $2.4 \mathrm{~kg}) \mathrm{vs}$ lean mass $(1.1$ to $1.2 \mathrm{~kg})[37,38]$. These reductions occurred in the context of a sustained elevation in spot urinary glucose excretion, which is associated with decreased total body weight and fat mass. Thus, the caloric loss from glucosuria, and not fluid loss, was responsible for the reductions [38]. This is supported by results from a small study finding that changes in extracellular water volume with SGLT-2is are transient, and not responsible for long-term weight loss with this drug class [39].

Similar results were observed in trials assessing body composition with other GLP-1RAs [32, 40, 41]. In a substudy of the LEAD-2 trial, liraglutide $1.8 \mathrm{mg}$ led to changes from baseline in fat mass and lean mass of $-2.4 \mathrm{~kg}$ and $-1.5 \mathrm{~kg}$, respectively, over 26 weeks in 37 participants with type 2 diabetes [40]. In a separate prospective case-series study investigating liraglutide in nine overweight or obese elderly individuals with uncontrolled type 2 diabetes on metformin, DXA demonstrated that mean fat mass was reduced by $1.5 \mathrm{~kg}$, but skeletal muscle index (a measure of muscle mass) improved [41]. A second prospective case-series study

( $n=178$ [semaglutide, $n=88$; canagliflozin, $n=90]$ ). Missing data were multiple imputed using data from participants within the same group defined by randomised treatment. Data are plotted for the first ten out of $500 \mathrm{impu}-$ tations. DBP, diastolic BP; SBP, systolic BP

evaluated liraglutide $0.9 \mathrm{mg}$ once daily in obese Japanese individuals over 24 weeks [32]. In that study $(n=9)$, body weight was reduced by $11.7 \%$. Body composition analysis from DXA scans showed that this was mostly caused by decreases in visceral fat mass (mean reduction: $11.9 \%$ ) and intrahepatic lipid content (mean reduction: $49.2 \%$ ) with no change in subcutaneous fat. Fat mass index also decreased (mean reduction: 10.9\%) whereas skeletal muscle mass remained unchanged [32]. While indirect comparisons across clinical trials should be interpreted with caution, given the heterogeneity of the study populations, these findings suggest that body composition changes with semaglutide are consistent with those in previous studies of other GLP-1RAs. These changes are supported by the proposed mechanisms of weight loss with GLP-1RAs through appetite modulation via the central nervous system with minimal effect on energy expenditure [42, 43], as well as through the increase of natriuresis caused by inhibition of the sodium-hydrogen ion transporter in the proximal tubule, which subsequently reduces sodium retention and extracellular fluid volume expansion [44]. An additional mechanism may be nausea/vomiting, which was 
Table 2 Body composition outcomes at week 52 ('On-treatment without rescue medication' data)

\begin{tabular}{|c|c|c|c|}
\hline & $\begin{array}{l}\text { Semaglutide } \\
1.0 \mathrm{mg}(n=88)\end{array}$ & $\begin{array}{l}\text { Canagliflozin } \\
300 \mathrm{mg}(n=90)\end{array}$ & $\operatorname{ETD}(95 \% \mathrm{CI})$ \\
\hline \multicolumn{4}{|l|}{ Total fat mass ${ }^{\mathrm{a}}$} \\
\hline Change at week $52, \mathrm{~kg}$ & $-3.41(0.51)$ & $-2.62(0.45)$ & $-0.79(-2.10,0.51)$ \\
\hline Change at week $52, \%$-point & $-1.43(0.39)$ & $-1.21(0.35)$ & $-0.21(-1.26,0.84)$ \\
\hline \multicolumn{4}{|l|}{ Total lean mass } \\
\hline Change at week $52, \mathrm{~kg}$ & $-2.26(0.30)$ & $-1.48(0.28)$ & $-0.78(-1.61,0.04)$ \\
\hline Change at week $52, \%$-point & $1.24(0.39)$ & $1.10(0.34)$ & $0.14(-0.89,1.17)$ \\
\hline \multirow{2}{*}{\multicolumn{4}{|c|}{$\begin{array}{l}\text { Total fat plus lean mass } \\
\text { (post hoc assessment) }^{\mathrm{b}}\end{array}$}} \\
\hline & & & \\
\hline Change at week $52, \mathrm{~kg}$ & -5.7 & -4.1 & \\
\hline \multicolumn{4}{|l|}{ Total fat mass:total lean mass, $\mathrm{kg}$} \\
\hline Change at week 52 & $-0.04(0.01)$ & $-0.03(0.01)$ & $-0.01(-0.04,0.02)$ \\
\hline \multicolumn{4}{|l|}{ Visceral fat mass } \\
\hline Change at week $52, \mathrm{~kg}$ & $-0.18(0.05)$ & $-0.11(0.04)$ & $-0.07(-0.20,0.06)$ \\
\hline Change at week $52, \%$-point & $-0.94(0.94)$ & $0.44(0.69)$ & $-1.38(-3.65,0.88)$ \\
\hline \multicolumn{4}{|l|}{ Waist circumference, $\mathrm{cm}$} \\
\hline Change at week $52^{\mathrm{c}}$ & $-3.9(5.6)$ & $-2.5(5.5)$ & \\
\hline
\end{tabular}

Data are mean (SE) unless otherwise specified and represent estimates from an ANCOVA with treatment, region and baseline value as fixed effects

Multiple imputation was used where missing data were imputed using observed data from participants within the same group defined by randomised treatment, using a regression model including region and stratification factor as categorical effects and data from baseline and all previous visits as covariates

Regions were defined as North America (USA and Canada); Region Europe (UK, Ireland and Sweden); or International Operations (Lebanon, Malaysia, Argentina, Mexico, Brazil and India)

${ }^{\text {a }}$ For total fat mass, responses were analysed with an ANCOVA with treatment and region as fixed factors and baseline value as covariate. Before analysis, missing data were multiple imputed using observed data from participants within the same group defined by randomised treatment, using a regression model including region as categorical effect and data from baseline as covariate

${ }^{\mathrm{b}}$ Not pre-specified for the substudy; data are calculated as the sum of the estimated change (mean [SD])

${ }^{\mathrm{c}}$ Not pre-specified for the substudy; data are mean (SD)

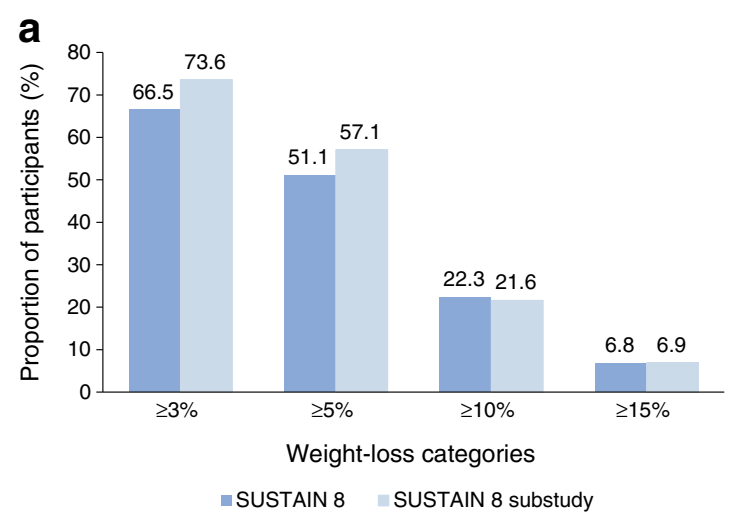

Fig. 5 Proportion of participants achieving weight loss $\geq 3 \%, 5 \%, 10 \%$ or $15 \%$ of body weight from baseline after 52 weeks of treatment with semaglutide $1.0 \mathrm{mg}$ (a) and canagliflozin $300 \mathrm{mg}$ (b) in SUSTAIN 8 $(n=788)$ and the SUSTAIN 8 substudy $(n=178)$. 'On-treatment without rescue medication' data. Missing data were multiple imputed using observed data from participants within the same group defined by randomised treatment, using a regression model including region and stratification factor as categorical effects and data from baseline and all

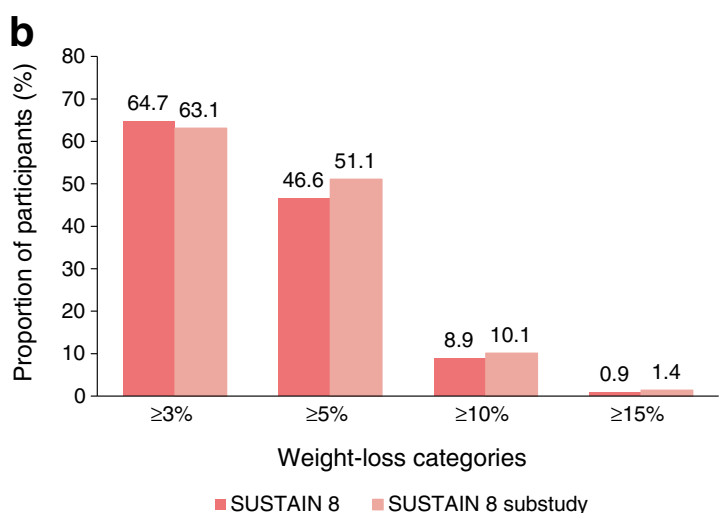

previous visits as covariates. Regions were defined as North America (USA and Canada); Region Europe (UK, Ireland and Sweden); or International Operations (Lebanon, Malaysia, Argentina, Mexico, Brazil and India). This post hoc comparison of change in body weight within the substudy vs the primary study was performed in order to confirm that weight loss in participants undergoing a DXA scan in the substudy was representative of the weight loss in the primary study 
shown to have a minimal effect on weight loss in a post hoc mediation analysis of semaglutide vs exenatide extended release and dulaglutide in the SUSTAIN 3 and 7 trials [45].

The positive effects of both treatments on weight loss demonstrated previously $[11-20,24]$ highlight the importance of newer agents among current pharmacological options, compared with older, standard approaches for type 2 diabetes that may increase or have little effect on weight [46]. However, the greater reduction of weight loss with semaglutide vs canagliflozin in the primary SUSTAIN 8 trial [17], when also taking into account the lack of statistical difference in body composition changes between treatments in this substudy, highlights the potential value of semaglutide in terms of weight management in individuals with uncontrolled type 2 diabetes on stable-dose metformin therapy.

\section{Strengths and weaknesses}

The strengths of this substudy include the methods and design of SUSTAIN 8, a double-blind randomised clinical trial with a global population, relatively long treatment period of 52 weeks, and relevant head-to-head comparison with a glucose-lowering medication with demonstrated efficacy in type 2 diabetes. In addition, analysis and quality assessments of the DXA scans were performed by one central imaging laboratory using one brand of scanner, reducing the likelihood of inconsistencies in bone and soft-tissue measurements that can occur due to variability of hardware and software packages between DXA equipment manufacturers [47].

DXA is one of the most popular and widely used noninvasive techniques for estimation of whole-body and regional body composition [47-49]. However, body thickness and hydration status can affect results [49], and lean muscle mass may also include non-muscle components, such as blood or interstitial fluid, leading to measurement error [50]. Moreover, the inability of DXA to distinguish different types of fat (visceral, subcutaneous, intramuscular) and lean soft tissues (muscle, organs) represents a practical limitation [49]. The lack of systematic collection of off-treatment DXA scans is a weakness of this substudy. Some participants only received baseline scans, and approximately a third did not have scans available for the confirmatory analysis, mostly due to these being taken out-of-window. However, results from the supplementary in-trial analysis, which included all available data, were similar to those observed in the confirmatory analysis and confirm the robustness of data. Finally, the SUSTAIN 8 trial did not include a placebo arm, meaning that all changes in body weight and composition reported here are comparisons between active treatments, and it cannot be concluded that all observed changes were entirely attributable to either treatment.

\section{Conclusion}

In the SUSTAIN 8 substudy, the changes in body composition between semaglutide and canagliflozin were not significantly different in participants with uncontrolled type 2 diabetes on stable-dose metformin therapy. Although numerical improvements in body composition were observed following treatment in both treatment arms, the specific impact of both treatments on body composition in the absence of a placebo arm is speculative at this stage.

Acknowledgements We thank all the participants, investigators and trialsite staff members who were involved in the conduct of the trial; E. Yildirim (Novo Nordisk A/S, Søborg, Denmark) for review and suggestions for revising the manuscript; and S. Vanderveen and F. Harris, MRes at AXON Communications, for medical writing and editorial assistance (funded by Novo Nordisk A/S, Denmark). Some of the data were presented at the 55th EASD Annual Meeting, Barcelona, 2019 (McCrimmon R et al. Oral presentation: presentation number 54).

Data availability Individual participant data will be shared in datasets in a de-identified/anonymised format. Datasets from Novo Nordisksponsored clinical research completed after 2001 for product indications approved in both the EU and USA will be shared. The study protocol and redacted Clinical Study Report (CSR) will be available according to Novo Nordisk data sharing commitments. The data will be available permanently after research completion and approval of product and product use in both EU and US. There is no end date. Data will be shared with bona fide researchers submitting a research proposal and requesting access to data, for use as approved by the Independent Review Board (IRB) according to the IRB Charter (see www.novonordisk-trials.com). The access request proposal form and the access criteria can be found at www.novonordisk-trials.com. The data will be made available on a specialised SAS data platform.

Funding This trial was supported by Novo Nordisk A/S, Denmark. The funding sources contributed to the design and conduct of the trials, the analysis and interpretation of the data, and the preparation, review and approval of the manuscript.

Duality of interest RJM reports grants from the Helmsley Trust, EU IMI, MRC, Diabetes UK and the JDRF during the conduct of the study and fees from Eli Lilly, Novo Nordisk and Sanofi outside the submitted work. JPF reports grants and personal fees from Novo Nordisk during the conduct of the study and grants and personal fees from Boehringer Ingelheim, BMS, Eli Lilly, Merck, Pfizer and Sanofi outside the submitted work. CWIR reports grants and other support from the Health Research Board and the Science Foundation Ireland during the conduct of the study. Outside the submitted work, he reports grants, personal fees and other support from AnaBio, AstraZeneca, Boehringer Ingelheim, Bristol-Myers Squibb, Eli Lilly, GI Dynamics, Janssen, Johnson \& Johnson, Keyron, Novo Nordisk and Sanofi. IL received research grants to her institution and consulting fees from Novo Nordisk during the conduct of the study. Outside the submitted work, she has received grants and/or personal fees from AstraZeneca, Boehringer Ingelheim, Eli Lilly, GI Dynamics, Intarcia, Mannkind, Merck, Mylan, Novartis, Novo Nordisk, Pfizer, Sanofi, TARGET PharmaSolutions and Valeritas. A-MC, NLL and DT are employees of Novo Nordisk A/S.

Contribution statement IL, A-MC, CWIR, DT and RJM participated in the design of this analysis. IL, A-MC, JF, CWIR, DT and RJM contributed to the conduct and data collection of the primary trial. NLL 
contributed to the data analysis. All authors interpreted the data and participated in writing the report, with the support of medical writing services provided by the funder. All authors read and approved the submitted version of the report. RJM is responsible for the integrity of this work as a whole.

Open Access This article is licensed under a Creative Commons Attribution 4.0 International License, which permits use, sharing, adaptation, distribution and reproduction in any medium or format, as long as you give appropriate credit to the original author(s) and the source, provide a link to the Creative Commons licence, and indicate if changes were made. The images or other third party material in this article are included in the article's Creative Commons licence, unless indicated otherwise in a credit line to the material. If material is not included in the article's Creative Commons licence and your intended use is not permitted by statutory regulation or exceeds the permitted use, you will need to obtain permission directly from the copyright holder. To view a copy of this licence, visit http://creativecommons.org/licenses/by/4.0/.

\section{References}

1. Gatineau M, Hancock C, Holman N et al (2014) Adult obesity and type 2 diabetes. Available from https://assets.publishing.service. gov.uk/government/uploads/system/uploads/attachment_data/file/ 338934/Adult_obesity_and type_2_diabetes_.pdf. Accessed 25 November 2019

2. Van Gaal L, Scheen A (2015) Weight management in type 2 diabetes: current and emerging approaches to treatment. Diabetes Care 38(6):1161-1172. https://doi.org/10.2337/dc14-1630

3. Castro AV, Kolka CM, Kim SP, Bergman RN (2014) Obesity, insulin resistance and comorbidities? Mechanisms of association. Arq Bras Endocrinol Metabol 58(6):600-609. https://doi.org/10.1590/ 0004-2730000003223

4. Ormazabal V, Nair S, Elfeky O, Aguayo C, Salomon C, Zuniga FA (2018) Association between insulin resistance and the development of cardiovascular disease. Cardiovasc Diabetol 17(1):122. https:// doi.org/10.1186/s12933-018-0762-4

5. Hubert HB, Feinleib M, McNamara PM, Castelli WP (1983) Obesity as an independent risk factor for cardiovascular disease: a 26-year follow-up of participants in the Framingham Heart Study. Circulation 67(5):968-977. https://doi.org/10.1161/01.cir.67.5.968

6. Davies MJ, D'Alessio DA, Fradkin J et al (2018) Management of hyperglycaemia in type 2 diabetes, 2018. A consensus report by the American Diabetes Association (ADA) and the European Association for the Study of Diabetes (EASD). Diabetologia 61(12):2461-2498. https://doi.org/10.1007/s00125-018-4729-5

7. American Diabetes Association (2019) 8. Obesity management for the treatment of type 2 diabetes: standards of medical care in diabetes-2019. Diabetes Care 41(Suppl 1):S81-S89. https://doi.org/10. 2337/dc19-S008

8. Pi-Sunyer FX (2009) The impact of weight gain on motivation, compliance, and metabolic control in patients with type 2 diabetes mellitus. Postgrad Med 121(5):94-107. https://doi.org/10.3810/ pgm.2009.09.2056

9. European Medicines Agency (2017) Ozempic (semaglutide) summary of product characteristics. Available from https://www. ema.europa.eu/en/documents/product-information/ozempic-eparproduct-information_en.pdf. Accessed 25 November 2019

10. Novo Nordisk (2017) Ozempic (semaglutide). Prescribing information. Available from https://www.novo-pi.com/ozempic.pdf. Accessed 25 November 2019

11. Sorli C, Harashima SI, Tsoukas GM et al (2017) Efficacy and safety of once-weekly semaglutide monotherapy versus placebo in patients with type 2 diabetes (SUSTAIN 1): a double-blind, randomised, placebo-controlled, parallel-group, multinational, multicentre phase 3a trial. Lancet Diabetes Endocrinol 5(4):251260. https://doi.org/10.1016/S2213-8587(17)30013-X

12. Ahrén B, Masmiquel L, Kumar H et al (2017) Efficacy and safety of once-weekly semaglutide versus once-daily sitagliptin as an add-on to metformin, thiazolidinediones, or both, in patients with type 2 diabetes (SUSTAIN 2): a 56-week, double-blind, phase 3a, randomised trial. Lancet Diabetes Endocrinol 5(5):341-354. https://doi.org/10.1016/s2213-8587(17)30092-x

13. Ahmann AJ, Capehorn M, Charpentier G et al (2018) Efficacy and safety of once-weekly semaglutide versus exenatide ER in subjects with type 2 diabetes (SUSTAIN 3): a 56-week, open-label, randomized clinical trial. Diabetes Care 41(2):258-266. https://doi.org/10. 2337/dc17-0417

14. Aroda VR, Bain SC, Cariou B et al (2017) Efficacy and safety of once-weekly semaglutide versus once-daily insulin glargine as addon to metformin (with or without sulfonylureas) in insulin-naive patients with type 2 diabetes (SUSTAIN 4): a randomised, openlabel, parallel-group, multicentre, multinational, phase 3a trial. Lancet Diabetes Endocrinol 5(5):355-366. https://doi.org/10. 1016/s2213-8587(17)30085-2

15. Rodbard HW, Lingvay I, Reed J et al (2018) Semaglutide added to basal insulin in type 2 diabetes (SUSTAIN 5): a randomized, controlled trial. J Clin Endocrinol Metab 103(6):2291-2301. https://doi.org/10.1210/jc.2018-00070

16. Pratley RE, Aroda VR, Lingvay I et al (2018) Semaglutide versus dulaglutide once weekly in patients with type 2 diabetes (SUSTAIN 7): a randomised, open-label, phase $3 \mathrm{~b}$ trial. Lancet Diabetes Endocrinol 6(4):275-286. https://doi.org/10.1016/s2213-8587(18) 30024-x

17. Lingvay I, Catarig AM, Frias JP et al (2019) Efficacy and safety of once-weekly semaglutide versus daily canagliflozin as add-on to metformin in patients with type 2 diabetes (SUSTAIN 8): a double-blind, phase $3 \mathrm{~b}$, randomised controlled trial. Lancet Diabetes Endocrinol 7(11):834-844. https://doi.org/10.1016/ s2213-8587(19)30311-0

18. Zinman B, Bhosekar V, Busch R et al (2019) Semaglutide once weekly as add-on to SGLT-2 inhibitor therapy in type 2 diabetes (SUSTAIN 9): a randomised, placebo-controlled trial. Lancet Diabetes Endocrinol 7(5):356-367. https://doi.org/10.1016/s22138587(19)30066-x

19. Capehorn MS, Catarig AM, Furberg JK et al (2019) Efficacy and safety of once-weekly semaglutide $1.0 \mathrm{mg}$ vs once-daily liraglutide $1.2 \mathrm{mg}$ as add-on to 1-3 oral antidiabetic drugs in subjects with type 2 diabetes (SUSTAIN 10). Diabetes Metab. https://doi.org/10.1016/ j.diabet.2019.101117

20. Marso SP, Bain SC, Consoli A et al (2016) Semaglutide and cardiovascular outcomes in patients with type 2 diabetes. N Engl J Med 375(19):1834-1844. https://doi.org/10.1056/NEJMoa1607141

21. Janssen Pharmaceuticals, Inc (2019) Invokana (canagliflozin) tablets. Prescribing information. Available from www.invokana. com/prescribing-information.pdf. Accessed 25 November 2019

22. Jakher H, Chang TI, Tan M, Mahaffey KW (2019) Canagliflozin review - safety and efficacy profile in patients with T2DM. Diabetes Metab Syndr Obes 12:209-215. https://doi.org/10.2147/dmso. s184437

23. Perkovic V, Jardine MJ, Neal B et al (2019) Canagliflozin and renal outcomes in type 2 diabetes and nephropathy. N Engl J Med 380(24):2295-2306. https://doi.org/10.1056/NEJMoa1811744

24. Seufert J (2015) SGLT2 inhibitors - an insulin-independent therapeutic approach for treatment of type 2 diabetes: focus on canagliflozin. Diabetes Metab Syndr Obes 8:543-554. https://doi. org/10.2147/dmso.s90662

25. International Conference on Harmonisation-World Health Organization Guideline for Good Clinical Practice (1996) ICH 
harmonised tripartite guideline good clinical practice. Available from https://apps.who.int/medicinedocs/en/m/abstract/Js22154en/. Accessed 25 November 2019

26. World Medical Association (2013) World Medical Association Declaration of Helsinki: ethical principles for medical research involving human subjects. JAMA 310(20):2191-2194. https://doi. org/10.1001/jama.2013.281053

27. Little RJA, Rubin DB (1987) Statistical analysis with missing data. John Wiley \& Sons, New York

28. Bretz F, Posch M, Glimm E, Klinglmueller F, Maurer W, Rohmeyer K (2011) Graphical approaches for multiple comparison procedures using weighted Bonferroni, Simes, or parametric tests. Biom J 53(6):894-913. https://doi.org/10.1002/bimj.201000239

29. Brownbill RA, Ilich JZ (2005) Measuring body composition in overweight individuals by dual energy x-ray absorptiometry. BMC Med Imaging 5(1):1. https://doi.org/10.1186/1471-2342-5-1

30. Van Gaal LF, Mertens IL, De Block CE (2006) Mechanisms linking obesity with cardiovascular disease. Nature 444(7121):875-880. https://doi.org/10.1038/nature05487

31. Sarin HV, Lee JH, Jauhiainen M et al (2019) Substantial fat mass loss reduces low-grade inflammation and induces positive alteration in cardiometabolic factors in normal-weight individuals. Sci Rep 9(1):3450. https://doi.org/10.1038/s41598-019-40107-6

32. Ishii S, Nagai Y, Sada Y et al (2019) Liraglutide reduces visceral and intrahepatic fat without significant loss of muscle mass in obese patients with type 2 diabetes: a prospective case series. J Clin Med Res 11(3):219-224. https://doi.org/10.14740/jocmr3647

33. Gill LE, Bartels SJ, Batsis JA (2015) Weight management in older adults. Curr Obes Rep 4(3):379-388. https://doi.org/10.1007/ s13679-015-0161-z

34. Kim B, Tsujimoto T, So R, Zhao X, Oh S, Tanaka K (2017) Changes in muscle strength after diet-induced weight reduction in adult men with obesity: a prospective study. Diabetes Metab Syndr Obes 10:187-194. https://doi.org/10.2147/dmso.s132707

35. DeFronzo RA, Tripathy D (2009) Skeletal muscle insulin resistance is the primary defect in type 2 diabetes. Diabetes Care 32(Suppl 2): S157-S163. https://doi.org/10.2337/dc09-S302

36. Ohta A, Kato H, Ishii S et al (2017) Ipragliflozin, a sodium glucose co-transporter 2 inhibitor, reduces intrahepatic lipid content and abdominal visceral fat volume in patients with type 2 diabetes. Expert Opin Pharmacother 18(14):1433-1438. https://doi.org/10. 1080/14656566.2017.1363888

37. Blonde L, Stenlof K, Fung A, Xie J, Canovatchel W, Meininger G (2016) Effects of canagliflozin on body weight and body composition in patients with type 2 diabetes over 104 weeks. Postgrad Med 128(4):371-380. https://doi.org/10.1080/00325481.2016.1169894

38. Bolinder J, Ljunggren Ö, Kullberg J et al (2012) Effects of dapagliflozin on body weight, total fat mass, and regional adipose tissue distribution in patients with type 2 diabetes mellitus with inadequate glycemic control on metformin. J Clin Endocrinol Metab 97(3):1020-1031. https://doi.org/10.1210/jc.2011-2260

39. Schork A, Saynisch J, Vosseler A et al (2019) Effect of SGLT2 inhibitors on body composition, fluid status and renin- angiotensin-aldosterone system in type 2 diabetes: a prospective study using bioimpedance spectroscopy. Cardiovasc Diabetol 18(1):46. https://doi.org/10.1186/s12933-019-0852-y

40. Jendle J, Nauck MA, Matthews DR et al (2009) Weight loss with liraglutide, a once-daily human glucagon-like peptide- 1 analogue for type 2 diabetes treatment as monotherapy or added to metformin, is primarily as a result of a reduction in fat tissue. Diabetes Obes Metab 11(12):1163-1172. https://doi.org/10.1111/j.14631326.2009.01158.x

41. Perna S, Guido D, Bologna C et al (2016) Liraglutide and obesity in elderly: efficacy in fat loss and safety in order to prevent sarcopenia. A perspective case series study. Aging Clin Exp Res 28(6):12511257. https://doi.org/10.1007/s40520-015-0525-y

42. Brown E, Wilding JPH, Barber TM, Alam U, Cuthbertson DJ (2019) Weight loss variability with SGLT2 inhibitors and GLP-1 receptor agonists in type 2 diabetes mellitus and obesity: mechanistic possibilities. Obes Rev 20(6):816-828. https://doi.org/10.1111/ obr.12841

43. Ryan D, Acosta A (2015) GLP-1 receptor agonists: nonglycemic clinical effects in weight loss and beyond. Obesity (Silver Spring) 23(6):1119-1129. https://doi.org/10.1002/oby.21107

44. Baretić M, Kušec V, Pavlić-Renar I (2018) Glucagon-like peptide-1 infusion suppresses aldosterone levels in healthy normal-weight individuals: double-blind, placebo-controlled crossover study. Diabetes Ther 9(6):2315-2324. https://doi.org/10.1007/s13300018-0517-y

45. Lingvay I, de la Rosa R, Marre M et al (2018) Minimal contribution of nausea or vomiting to superior semaglutide-mediated weight loss vs exenatide and dulaglutide in type 2 diabetes. Diabetologia 61(Suppl 1):765 (Abstract 765)

46. Hermansen K, Mortensen LS (2007) Bodyweight changes associated with antihyperglycaemic agents in type 2 diabetes mellitus. Drug Saf 30(12):1127-1142. https://doi.org/10.2165/00002018200730120-00005

47. Tosato M, Marzetti E, Cesari M et al (2017) Measurement of muscle mass in sarcopenia: from imaging to biochemical markers. Aging Clin Exp Res 29(1):19-27. https://doi.org/10.1007/s40520016-0717-0

48. Lee SY, Gallagher D (2008) Assessment methods in human body composition. Curr Opin Clin Nutr Metab Care 11(5):566-572. https://doi.org/10.1097/MCO.0b013e32830b5f23

49. Prado CM, Heymsfield SB (2014) Lean tissue imaging: a new era for nutritional assessment and intervention. J Parenter Enter Nutr 38(8):940-953. https://doi.org/10.1177/0148607114550189

50. Weiss EP, Jordan RC, Frese EM, Albert SG, Villareal DT (2017) Effects of weight loss on lean mass, strength, bone, and aerobic capacity. Med Sci Sports Exerc 49(1):206-217. https://doi.org/10. 1249/mss.0000000000001074

Publisher's note Springer Nature remains neutral with regard to jurisdictional claims in published maps and institutional affiliations. 